TITLE:

\title{
Fast T-Type Photochromism of Colloidal Cu-Doped ZnS Nanocrystals
}

$\operatorname{AUTHOR}(S)$ :

Han, Yulian; Hamada, Morihiko; Chang, I-Ya; Kim, Hyeon-Deuk; Kobori, Yasuhiro; Kobayashi, Yoichi

\section{CITATION:}

Han, Yulian ...[et al]. Fast T-Type Photochromism of Colloidal Cu-Doped ZnS

Nanocrystals. Journal of the American Chemical Society 2021, 143(5): 2239-2249

\section{ISSUE DATE:}

2021-02-10

URL:

http://hdl.handle.net/2433/261702

\section{RIGHT:}

This document is the Accepted Manuscript version of a Published Work that appeared in final form in Journal of the American Chemical Society, copyright ( $\odot$ American Chemical Society after peer review and technical editing by the publisher. To access the final edited and published work see https://doi.org/10.1021/jacs.0c10236.; The full-text file will be made open to the public on 12 January 2022 in accordance with publisher's 'Terms and Conditions for SelfArchiving': この論文は出版社版でありません。引用の際には出版社版をご確認ご利用ください。; This is not the published version. Please cite only the published version. 


\title{
Fast T-Type Photochromism of Colloidal Cu-Doped ZnS Nanocrystals
}

\author{
Yulian Han†, Morihiko Hamada‡, I-Ya Chang ${ }^{\S}$, Kim Hyeon-Deuk ${ }^{\S *}$, Yasuhiro Kobori‡, ${ }^{\text {II* }}$ and Yoichi \\ Kobayashit,*
}

†Department of Applied Chemistry, College of Life Sciences, Ritsumeikan University, 1-1-1 Nojihigashi, Kusatsu, Shiga 525-8577, Japan.

‡Molecular Photoscience Research Center, Kobe University, 1-1, Rokkodai-cho, Nada-ku, Kobe 657-8501, Japan.

ॠDepartment of Chemistry, Graduate School of Science, Kobe University, 1-1 Rokkodai-cho, Nada-ku, Kobe 6578501, Japan

§Department of Chemistry, Kyoto University, Kyoto, 606-8502, Japan.

\begin{abstract}
This paper reports on durable and nearly temperature-independent (at 298-328 K) T-type photochromism of colloidal Cu-doped ZnS nanocrystals (NCs). The color of Cu-doped ZnS NC powder changes from pale yellow to dark gray by UV light irradiation, and the color changes back to pale yellow on a time scale of several tens of seconds to minutes after stopping the light irradiation, while the decoloration reaction is accelerated to submillisecond in solutions. This decoloration reaction is much faster than those of conventional inorganic photochromic materials. Origin of the reversible photoinduced coloration is revealed to be a strong optical transition involving a delocalized surface hole which survives over a minute escaped from intraparticle carrier recombination due to electron-hopping dissociation. ZnS NCs can be easily prepared in water-mediated one-pot synthesis and are less toxic. Therefore, they are promising for large-scale photochromic applications such as windows and building materials in addition to conventional photochromic applications. Moreover, the present study demonstrates importance of excited carrier dynamics and trap depths resulting in coloration over minutes not only for photochromic nanomaterials but also for various advanced photofunctional materials, such as long persistent luminescent materials and photocatalytic nanomaterials.
\end{abstract}

\section{INTRODUCTION}

Photochromism, which is defined as a reversible transformation of light between two structural isomers, has been extensively studied for decades because they can switch various physical, chemical, and biological properties by light irradiation. ${ }^{1-4}$ Thus far, a number of photochromic materials have been reported in both organic and inorganic materials. ${ }^{2}$ Organic photochromic materials (e.g. azobenzenes, spiropyrans, naphthopyrans, diarylethenes) have been widely studied not only for fundamental researches but also for industrial applications. Among these, fast thermally reversible (T-type) photochromic compounds, whose time scales of the thermal back reactions are sub-microseconds to seconds (e.g. bridged-imidazole dimers, ${ }^{5-10}$ oxazines, ${ }^{11-13}$ and naphthopyran derivatives ${ }^{14-}$ ${ }^{18}$ ), are especially promising for ophthalmic lenses, fluorescence switches for bioimaging, 19,20 and holographic 3D displays. ${ }^{21-23}$ These materials can tune colors and colorfading speeds from tens of nanoseconds to tens of seconds. However, multiple synthetic procedures and difficulties in preparing a single chromophore with black color are some disadvantages of these organic fast photochromic materials. Such disadvantages hinder their large-scale industrial applications such as windows and building materials, with low costs.

Large-scale photochromic materials can be easily prepared using inorganic photochromic materials such as sil- ver halide glasses, ${ }^{2} \mathrm{WO}_{3},{ }^{24,25}$ and $\mathrm{ZnS}^{26-29}$ However, most photochromic reactions of bulk inorganic materials have poor photosensitivity and very slow fading speeds. For example, more than a century ago, bulk $\mathrm{ZnS}$ and a mixture of $\mathrm{BaSO}_{4}$ and $\mathrm{ZnS}$ (lithopone) were reported to exhibit photoinduced darkening by prolonged UV light irradiation. ${ }^{26,27}$ It was assumed that photodarkening was caused by the formation of $\mathrm{Zn}$ on the surface and that the decoloration reaction to the original white color was caused by the oxidation of $\mathrm{Zn}$ to $\mathrm{ZnO} .^{27-30}$ However, the coloration and decoloration reactions of bulk $\mathrm{ZnS}$ and lithopone were sluggish with more than a hour, and the mechanism was not examined in detail, i.e., whether metal zinc was indeed formed or not. Therefore, it was difficult to apply these inorganic photochromic materials to industrial applications instead of organic photochromic materials used in the industry. ZnS has low toxicity and has been widely used in industry such as in electroluminescent devices, ${ }^{31,32}$ afterglow luminescence materials, ${ }^{33-35}$ and optical windows for infrared regions. ${ }^{36}$ If fast and photosensitive photochromic reactions, such as those in organic photochromic materials, can be achieved using inorganic photochromic materials (e.g. $\mathrm{ZnS}$ ), these materials will overcome the limitation of conventional organic materials and expand the versatility of photochromic materials for practical applications.

In this paper, we report fast and reversible photochromic reactions in solids and solutions of $\mathrm{Cu}$-doped col- 
loidal ZnS nanocrystals (NCs) in a minute. Cu-doped colloidal semiconductor NCs have been extensively studied for applications to luminescent materials, photocatalysts, and optoelectronic devices for several decades. ${ }^{37-50}$ However, thus far, very few studies has investigated their photochromic properties. ${ }^{51-53}$ Although a number of studies on the combination of photochromic organic molecules and nonphotochromic inorganic nanomaterials have been reported, ${ }^{54}$ there are limited studies on photochromic inorganic nanomaterials, such as $\mathrm{Ag}, 55,56 \mathrm{WO}_{3}, 57,58 \mathrm{ZnO},{ }^{59-62} \mathrm{TiO}_{2}$ nanoparticles, ${ }^{51-53,62,63}$ and titanate(IV) nanosheets. ${ }^{64}$ However, the forward or backward reactions in these inorganic photochromic reactions are induced under specific conditions such as light irradiation (P-type), exposure to molecular oxygen and ozone, or under magnetic fields. Because large quantities of inexpensive ZnS NCs can be easily prepared as compared with conventional organic photochromic materials, inorganic photochromic nanomaterials have a potential for large-scale industrial applications.

In addition, we reveal that the origin of the reversible photoinduced coloration of Cu-doped ZnS NCs is a strong optical transition involving a long-lived delocalized surface hole escaped from intraparticle carrier recombination due to electron-hopping dissociation. While there are several reports on inorganic photochromic materials utilizing the ultra long-lived excited carriers as a colored species such as $\mathrm{TiO}_{2}$ and $\mathrm{ZnO}$ nanomaterials, ${ }^{51,62,63}$ this study is the first report on fast $\mathrm{T}$-type photochromism by tuning the lifetimes of excited carriers in the air. Moreover, ultra longlived excited carriers have been received particular attention these days in organic long persistent luminescent materials ${ }^{65}$ and photocatalytic nanomaterials. ${ }^{66-68}$ Therefore, detailed analyses of the excited carriers-induced photochromic reaction at the atomic and molecular levels and exploring novel photochromic nanomaterials are important not only for photochromic materials but also for various advanced photofunctional materials utilizing longlived excited carriers.

\section{RESULTS AND DISCUSSION}

As described in the experimental section, ZnS NCs and $\mathrm{Cu}$-doped ZnS NCs were synthesized in aqueous solutions using 3-mercaptopropionic acid (MPA) as a capping reagent.

X-ray diffraction (XRD) measurements showed that the crystal structures of $\mathrm{ZnS}$ and $\mathrm{Cu}$-doped $\mathrm{ZnS}$ NCs were zincblende regardless of the amount of $\mathrm{Cu}$ (Figure S1). Transmission electron microscopy measurements showed that the average diameter of NCs was 3-4 nm (Figures 1 and S3). The $\mathrm{Cu}$-to $\mathrm{Zn}$ atom ratio was set to $1 \%-5 \%$, which was confirmed by X-ray fluorescence spectroscopy. When $\mathrm{Cu}^{2+}$ was used as a precursor for the dopant in $\mathrm{ZnS} \mathrm{NCs}$,
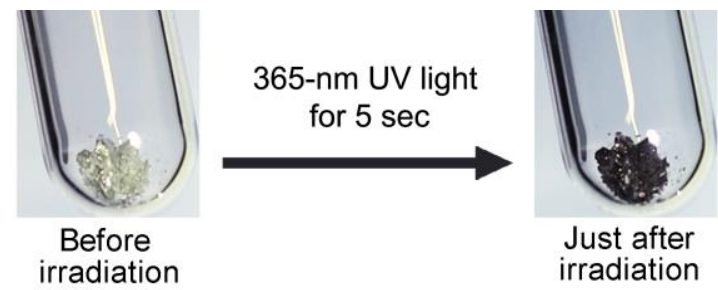

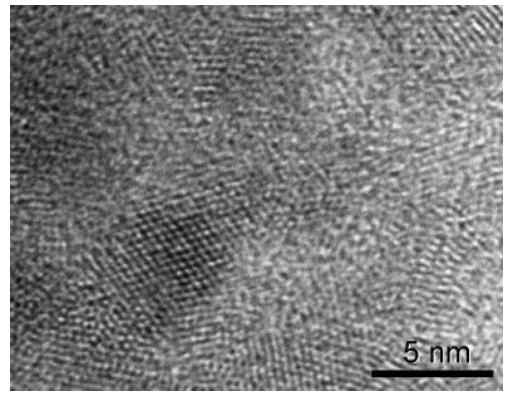

Figure 1. TEM image of 1\% Cu-doped ZnS NCs.

electron paramagnetic resonance (EPR) spectroscopy showed that the valence of doped $\mathrm{Cu}$ was +1 , as explained later. The organic capping reagents of NCs in solids were characterized in detail by attenuated total reflection Fourier transform infrared (ATR-FTIR) spectroscopy (Figure S4). This implies that (1) the thiol groups are most probably bound to the surface of ZnS NCs, (2) the carboxyl groups of MPA are deprotonated, and (3) the adsorbed water exists at the surface of NCs owing to the hydrogen bonding network between carboxylate anions.

Before ultraviolet (UV) light irradiation, the color of $\mathrm{ZnS}$ NC powders was white. However, with the increase in the concentration of doping $\mathrm{Cu}$ ions, the color changed from white to pale yellow $(1 \%$ and $3 \% \mathrm{Cu})$ and brown $(5 \% \mathrm{Cu})$. The pale yellowish color may be due to the increased density of states around the valence band owing to $\mathrm{Cu}$ ion doping. ${ }^{69}$ In addition, a small amount of the $\mathrm{Cu}_{2-x} \mathrm{~S}$ domain, which was not detected in XRD measurements, may be another reason for the pale yellow and brown colors before light irradiation, as discussed later. The absorption, diffuse reflectance and emission spectra of solids and solutions are shown in the supporting information (Figures S5 and S6). Notably, a green emission (the peak is located at $510 \mathrm{~nm}$ ) was observed in $1 \%$ and $3 \% \mathrm{Cu}$-doped $\mathrm{ZnS}$ NC solids upon excitation with $317 \mathrm{~nm}$, while a blue emission was observed in undoped ZnS NCs under the same excitation condition. Green emission is a characteristic feature of the doped $\mathrm{Cu}$ ion, which indicates that $\mathrm{Cu}$ ion was successfully doped in $\mathrm{ZnS}$ NCs.

Figure 2 shows the photographs of the color change of the powder of 1\% Cu-doped ZnS NCs before and after irradiation with continuous wave (CW) UV light (365 nm, 500 $\mathrm{mW} \mathrm{cm}^{-2}$ ) at room temperature (RT). The color-changing process can be seen in the supporting movie. The paleyellow powder turned black in $5 \mathrm{~s}$ under UV light irradiation. After stopping light irradiation, the black powder quickly returned to the original color after approximately $1 \mathrm{~min}$ at RT. The fast coloration and decoloration reactions

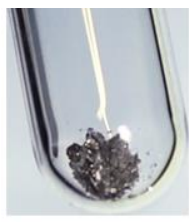

After $1 \mathrm{sec}$

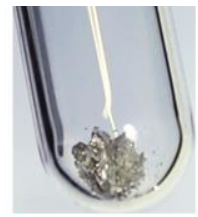

$10 \mathrm{sec}$

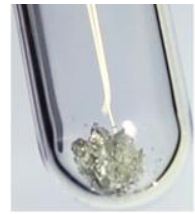

$1 \mathrm{~min}$

Figure 2. (a) Photographs of the photochromic reaction of the powder of $1 \% \mathrm{Cu}$-doped ZnS NCs upon UV light irradiation (365 $\mathrm{nm}, 500 \mathrm{~mW} \mathrm{~cm}^{-2}$ ). 
(a)

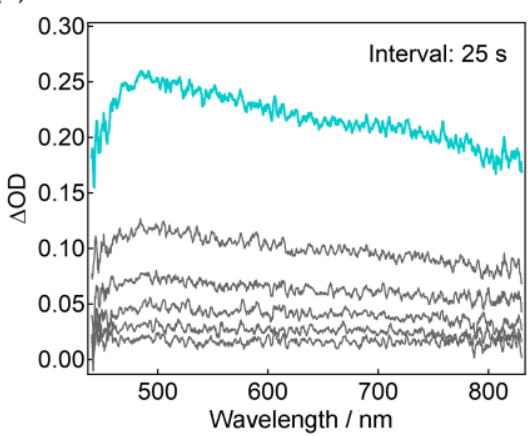

(b)

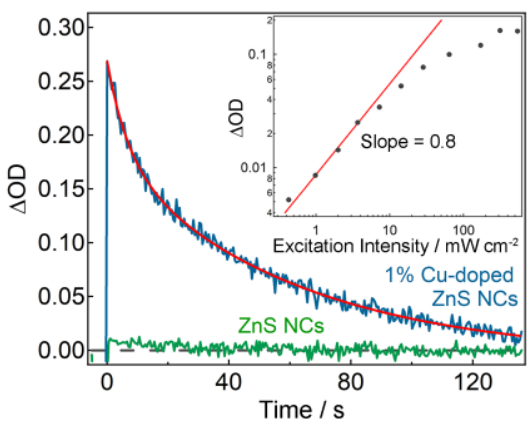

Figure 3. (a) Time evolution of diffuse reflectance spectra of the powder of $1 \% \mathrm{Cu}$-doped $\mathrm{ZnS}$ NCs after irradiation with CW UV light ( $365 \mathrm{~nm}, 18 \mathrm{~mW} \mathrm{~cm}^{-2}$ ) for 5 seconds. (b) Time evolution of the differential diffuse reflectance probed at $500 \mathrm{~nm}$. Inset, the $\triangle O D$ as a function of the excitation intensity.

can be repeated more than 20 times under the same irradiation condition. This result indicates that the powder of colloidal $\mathrm{Cu}$-doped $\mathrm{ZnS}$ NCs shows durable and relatively fast photochromic reactions in the solid state. The durability of the photochromic reaction was further revealed later (Figure 6).

Figure 3 a shows the time evolution of the differential diffuse reflectance spectra of the powder of $1 \% \mathrm{Cu}$-doped ZnS NCs after CW UV light irradiation (365 nm, $18 \mathrm{~mW}$ $\mathrm{cm}^{-2}$ ). A broad absorption band in the visible to nearinfrared light regions was observed by UV light irradiation. A broad absorption peak was observed at $\sim 500 \mathrm{~nm}$. The absorption band decays on a time scale of tens of seconds to minutes without changing the spectral shape. After 2 min, the signals almost completely reverted to those observed in the original spectra. However, the absorbance change of the powder of undoped ZnS NCs was only approximately $4 \%$ compared with that of $1 \% \mathrm{Cu}$-doped $\mathrm{ZnS}$ NCs under the same excitation condition (Figure 3b). Notably, the photodarkening reactions of bulk $\mathrm{ZnS}$ do not occur even under intense UV light irradiation (365 nm, 500 $\mathrm{mW} \mathrm{cm} \mathrm{cm}^{-2}$ ) at $77 \mathrm{~K}$. On the other hand, the powders of colloidal ZnS NCs and Cu-doped ZnS NCs turned light gray and dark gray upon UV irradiation at $77 \mathrm{~K}$, respectively (Figure S7). This result suggests that the photoinduced color change is a characteristic feature of NCs, and the Cu doping considerably enhances the coloration reaction.

For bulk ZnS, it has been reported that the origin of the darkening by prolonged light irradiation is the formation of metal zinc. ${ }^{28}$ However, the origin of the coloring of $\mathrm{Cu}$ doped ZnS NCs may differ from that of bulk ZnS because the photosensitivity and rate of coloration and decoloration of the $\mathrm{Cu}$-doped $\mathrm{ZnS}$ NCs considerably differ from those of bulk ZnS. If metallic zinc is formed by light irradiation, the photoinduced absorption will follow the quadratic dependence on the excitation intensity in the low excitation intensity regime because two electrons are necessary to produce metallic $\mathrm{Zn}$ from $\mathrm{ZnS}$. We investigated the excitation intensity dependence on the photoinduced absorption of $1 \% \mathrm{Cu}$-doped $\mathrm{ZnS}$ NC powder using a CW UV LED (365 nm, 0.43-540 $\mathrm{mW} \mathrm{cm}^{-2}$ for $1 \mathrm{~s}$ ). The number of excitons per $\mathrm{NC}$ was estimated to be $2.2 \times 10^{-2}\left(0.43 \mathrm{~mW} \mathrm{~cm}^{-2}\right)$ to 28 (540 $\mathrm{mW} \mathrm{cm}^{-2}$; the detailed calculation is shown in the supporting information). This result suggests that the excitation power less than $4 \mathrm{~mW} \mathrm{~cm}^{-2}$, which corresponds to the number of excitons per $\mathrm{NC} \sim 0.2$, could be regarded as the low excitation regime. The inset in Figure $3 \mathrm{~b}$ shows the logarithmic plot of $\triangle O D$ as a function of the excitation intensity. The slope of the line in the low excitation regime is $\sim 0.6-0.8$. This result shows that photoinduced absorption is formed by the one photon process. The effects of the gradual saturation and the reabsorption of the photoproduct on the slope can be neglected based on the kinetic simulation shown in the supporting information (Figure S9).

Figure $3 \mathrm{~b}$ shows the time evolution of the differential diffuse reflectance of the powders of 1\% Cu-doped $\mathrm{ZnS}$ NCs and ZnS NCs probed at $500 \mathrm{~nm}$. The decay shows nonsingle exponential decay behavior. The decay was tentatively fitted with the bi-exponential decay kinetics and the lifetimes were $6.0 \mathrm{~s}(30 \%)$ and $54 \mathrm{~s}(70 \%)$, respectively. As will be discussed later, the origin of the coloration is a long-lived delocalized surface hole, and the color fading process occurs via the hole trapping by adsorbed water at the surface of NCs and the charge recombination. The fast decay component is probably assigned to the hole trapping by the adsorbed water as shown in Figure S16b, and the slower component is mainly assigned to the charge recombination. 3\% Cu-doped $\mathrm{ZnS}$ NCs exhibit a photochromic reaction similar to that of $1 \% \mathrm{Cu}$-doped $\mathrm{ZnS}$ NCs (Figure S10). However, 5\% Cu-doped ZnS NCs did not exhibit the photochromic reaction upon UV light irradiation. EPR measurements revealed that $\mathrm{Cu}^{2+}$ was observed in $5 \%$ $\mathrm{Cu}$-doped $\mathrm{ZnS}$ NCs solids even before the UV light irradiation. Considering that the color of $5 \%-\mathrm{Cu}$-doped $\mathrm{ZnS} \mathrm{NCs}$ is brown and $\mathrm{Cu}^{2+}$ was observed before UV light irradiation in 5\% Cu-doped $\mathrm{ZnS}$ NCs (Figure S18), it is expected that the $\mathrm{Cu}_{2-\mathrm{x}} \mathrm{S}$ domain, whose color is dark brown, is slightly formed in 5\%-Cu-doped $\mathrm{ZnS} \mathrm{NCs}$ and the domain prevents the photochromic reaction of $\mathrm{ZnS}$ NCs. Since $\mathrm{Cu}_{2-x} \mathrm{~S}$ was not observed at all in XRD measurements, the domain may be significantly small. 
Interestingly, the photochromic reaction can be also observed in the powder made by mixing the $\mathrm{Cu}$-precursor and undoped ZnS NCs in water and precipitating with ethanol at RT (Figure S11). The spectral shape and decay kinetics were similar to those of $\mathrm{Cu}$-doped $\mathrm{ZnS}$ NCs. The result shows that the $\mathrm{Cu}$ ion was doped into $\mathrm{ZnS}$ NCs or adsorbed on the surface of NCs simply by mixing the $\mathrm{Cu}$ precursor with the ZnS NCs solution; the doped $\mathrm{Cu}$ ion promotes the photochromic reaction. This reference experiment shows that the surface of ZnS NCs is essential in the photochromic reaction of Cu-doped ZnS NCs.

It should be noted that the rate of decoloration of $\mathrm{Cu}$ doped ZnS NC solids was slightly different for different batches even in the same synthetic procedure (Figure S14). This is most probably due to the surface of NCs and microenvironments of NCs. The broad absorption band at approximately $3270 \mathrm{~cm}^{-1}$ in FTIR measurements shows the hydrogen bonding network at the surface of NCs. Therefore, it is expected that the carboxylate anions of the ligands accommodate water even in the solids. To investigate the effect of the adsorbed water on the surface of the NCs, the decoloration process was compared before and after the drying process under vacuum at $313 \mathrm{~K}$ for $1 \mathrm{~h}$. We observed that the amplitude of the broad absorption band at approximately $3270 \mathrm{~cm}^{-1}$, which is assigned to hydrogen bonds, decreased after the drying process under vacuum (Figure S15a). This result suggests that the adsorbed water trapped by the carboxylate anion decreases. The decoloration process was decelerated to several to tens-of minutes (Figure S15b), which indicated that the adsorbed water was an important factor for the fast photochromic reaction of $\mathrm{Cu}$-doped $\mathrm{ZnS} \mathrm{NCs}$. However, it is worth noting that the decoloration process of bulk $\mathrm{ZnS}$ and lithopone usually requires several hours. This observation suggests that the dried powder of $\mathrm{Cu}$-doped $\mathrm{ZnS}$ NCs still exhibits a relatively fast photochromic reaction as compared with bulk materials.

The photochromic reaction of Cu-doped ZnS NCs can be also observed in water solution and a drop-casted thin film (Figures S16 and S17), although the decoloration reaction is considerably different from those in powder. The submillisecond transient absorption spectra were measured by a randomly-interleaved pulse train (RIPT) method. ${ }^{70} \mathrm{In}$ the case of the water solution of Cu-doped $\mathrm{ZnS}$ NCs, the photoinduced absorption instantaneously generated by a 355-nm excitation pulse and the signal quickly decayed within a millisecond (Figures S16). The transient absorption signal does not depend on the molecular oxygen and can be repeatedly observed over $1 \mathrm{~h}$ irradiation without any photodegradation. The photochormic reaction of a drop-casted film is also accelerated as compared to those in powder (Figures S17). The acceleration of the decoloration reaction in solution and a thin film suggests that adsorbed water and interparticle reactions are involved in the photochromic reaction mechanism as explained later.

To reveal the photochromic reaction mechanism, we analyzed the EPR spectra of the powders of $1 \% \mathrm{Cu}$-doped $\mathrm{ZnS}$ $\mathrm{NC}$ and undoped ZnS NC solids at $77 \mathrm{~K}$ and RT. The powder samples were degassed under vacuum in EPR quartz tubes. Figures $4 \mathrm{a}$ and $4 \mathrm{~b}$ show the photo-EPR spectra of $1 \% \mathrm{Cu}$ doped ZnS NCs and undoped ZnS NCs at RT, which were (a) $1 \%$ Cu-doped ZnS NCs

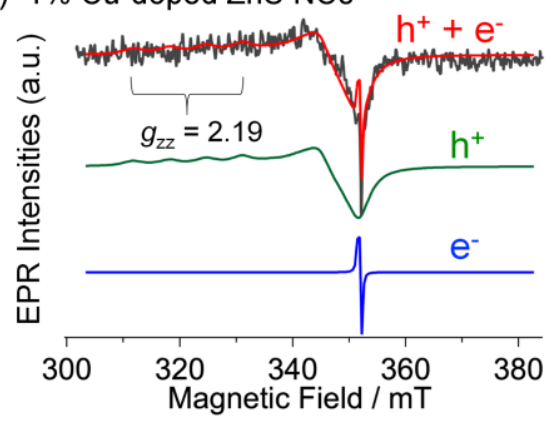

(b) ZnS NCs

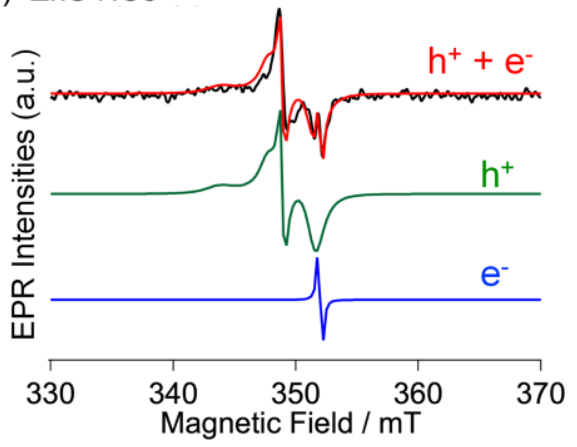

Figure 4. Photo-EPR spectra (black lines) of the powders of (a) Cu-doped ZnS NCs and (b) undoped ZnS NCs at RT. Simulated EPR spectra are shown by the red spectra those of which were decomposed to the computed spectra by holes (green) and electrons (blue) with applying the random rotational dynamic model. The microwave frequencies were 9852.772 MHz in (a) and $9853.678 \mathrm{MHz}$ in (b).

obtained by subtracting the EPR spectra under CW UV light (365 nm, $100 \mathrm{~mW} \mathrm{~cm}^{-2}$ ) irradiation from the data in the dark experiments. In Figure 4a, the photo-EPR spectrum is explained by the sum of the sharp line with $g=1.999$ (blue spectrum) and a broad line (green spectrum) with the ganisotropy of $g_{\mathrm{xx}}=2.017, g_{\mathrm{yy}}=2.018$, and $g_{\mathrm{zz}}=2.189$; the broad low-field side tail around $g_{\mathrm{zz}}=2.19$ is explained by an anisotropic hyperfine (HF) coupling with $A_{\mathrm{xx}}=1.8 \mathrm{mT}$, $A_{\mathrm{yy}}=1.7 \mathrm{mT}$, and $A_{\mathrm{zz}}=7.0 \mathrm{mT}$ from a copper nuclear spin (I $=3 / 2$ ) by a lineshape analysis, as detailed in the supporting information. ${ }^{71}$ The blue sharp contribution around the higher field region ( $g=1.999)$ is attributed to trapped electrons $\left(\mathrm{e}^{-}\right)$as reported around $g=1.996$ to be the Fcenter, ${ }^{72}$ although the g-anisotropy with $g_{\|}=2.000$ and $g_{\perp}$ $=1.994$ was reported to be identified in the bulk ZnS powder at $77 \mathrm{~K}$. This means that $\mathrm{e}^{-}$is highly mobile at RT within the NCs.

The entire broad lineshape in Figure 4a is similar to the EPR spectra of $\mathrm{Cu}^{2+\bullet}$ in axially distorted octahedral sites. ${ }^{73,74}$ In the absence of UV-light irradiation, we did not observe this broad line at $T=77 \mathrm{~K}$ (Figure S19) and at RT, although the oxidation number of the $\mathrm{Cu}$-precursor was +2 before the doping. This is rationalized by the reduction of the precursor $\mathrm{Cu}(\mathrm{II})$ to $\mathrm{Cu}(\mathrm{I})$ by the thiol groups, constituting the EPR-silent $\mathrm{Cu}^{+}$-doping ${ }^{69}$ with the $\mathrm{ZnS} \mathrm{NCs.}$

Thus, the light-induced broad EPR signal in Figure 4a may originate from the photo-oxidation of $\mathrm{Cu}^{+}$which is coordinated by $\mathrm{S}^{2-}$ and the generation of $\mathrm{Cu}^{2+\bullet}$ as a trapped 
hole $\left(\mathrm{h}^{+}\right)$in $\mathrm{Cu}$-doped $\mathrm{ZnS}$ NCs. However, the spectral width $(\approx 20 \mathrm{mT})$ of the unresolved lower-field transition region (around $B_{0}=322 \mathrm{mT}$ in Figure $4 \mathrm{a}$ ) by $g_{\mathrm{zz}}=2.19$ was narrower than the corresponding reported widths of c.a. $50 \mathrm{mT}$ comprising the broad four-line splitting by $A_{\mathrm{zz}} \approx 18$ mT of coordinated $\mathrm{Cu}^{2+\bullet} \cdot{ }^{73,74}$ This effect was more clearly observed at $T=77 \mathrm{~K}$ in $\mathrm{Cu}$-doped $\mathrm{ZnS}$ at $g_{\mathrm{zz}}=2.18$, as shown in Figure S20a. Thus, $A_{\mathrm{zz}}=7 \mathrm{mT}$ in this system may reflect a limited spin density $\left(\rho_{\mathrm{Cu}}\right)$ at the copper site estimated to be $\rho_{\mathrm{Cu}}=7 \mathrm{mT} / 18 \mathrm{mT}=0.4$, which indicates that the residual spin is located at the coordinating sulfur atoms $\left(\rho_{\mathrm{S}}=0.6\right)$ in $\mathrm{h}^{+}$, and a charge-resonance between $\mathrm{Cu}^{2+\bullet} \cdot \ldots \mathrm{S}^{2-}$ and $\mathrm{Cu}^{+} \cdots \mathrm{S}^{-\bullet}$ is formed. This coincides with reported interpretations on the electronic structure of trapped $\mathrm{Cu}^{2+\bullet}$ in $\mathrm{Cu}$-doped $\mathrm{ZnS}^{69}$ and with the photoinduced absorption band around the visible light region as the charge-transfer (CT) transition from the valence band (VB) in ZnS to the oxidized site in bulk Cu-doped ZnS crystals. ${ }^{75}$ Notably, such delocalized electronic characters both in the oxidized site and in the $\mathrm{ZnS} \mathrm{VB}$ may enhance the oscillator strength of the CT transition, as confirmed by a molecular orbital calculation (vide infra). The very broad optical absorption in Figure 3a is also compatible with the CT-transition feature from the VB to the trapped $\mathrm{Cu}^{2+\bullet}$ and thus suggests a large reorganization energy $(\lambda)^{76}$ for the hole de-trapping.

For undoped ZnS NCs (Figure 4b), the entire spectrum width $(\approx 10 \mathrm{mT})$ is much narrower than that of $\mathrm{h}^{+}$(green line in Figure $4 \mathrm{a}$ ) in the $\mathrm{Cu}$-doped $\mathrm{ZnS}$ NCs, which suggests that $\mathrm{h}^{+}$is trapped at the sulfur atom. ${ }^{72}$ The very sharp EPR component at $g=1.999$ (blue line in Figure $4 \mathrm{~b}$ ) is observed in the spectrum as well as in the blue spectrum in Figure $4 \mathrm{a}$, which implies that both $\mathrm{h}^{+}$and $\mathrm{e}^{-}$were generated by light irradiation. Nevertheless, the spectral shape was modulated by temperature, as shown by the green lines in Figures $4 \mathrm{~b}$ and S20b. At RT, the center peak intensity at $g=$ 2.025 is very strong in Figure $4 \mathrm{~b}$, while the intensities at the lower and higher field sides are more prominent in the anisotropic line shape in Figure S20b. This result indicates an involvement of the pseudo-rotation of charges in NCs. Therefore, we performed spectrum computations of the EPR lineshapes by taking into account the random rotation of radicals using an interexchange jump model among three representative g-tensor configurations considered in the presence of an external magnetic field, as detailed in the supporting information with Figure S21. The EPR lineshape shown in Figure $4 \mathrm{~b}$ was fit by setting $g_{\mathrm{xx}}=2.0010$, $g_{\text {yy }}=2.0010$, and $g_{\text {zz }}=2.0488$ with $\tau_{\text {hop }}=8.0$ ns which denotes the time constant for the jumps between the rotational conformations. This motional narrowing effect in $\mathrm{h}^{+}$ is coincident with the sharp single resonance lines observed in $\mathrm{e}^{-}$around the higher field region $(g=1.999)$, as shown by the blue lines in Figure 4, while the g-anisotropy of $g_{\mathrm{xx}}=1.940, g_{\mathrm{yy}}=1.940$ and $g_{\mathrm{zz}}=1.999$ was conclusive in Figure S20 at $77 \mathrm{~K}$ in $\mathrm{e}^{-}$. Under cryogenic conditions, the broad EPR line was interpreted by $g_{\mathrm{xx}}=2.005 g_{\mathrm{yy}}=2.035$, and $g_{\mathrm{zz}}=2.065$ (Figure S20b) as $\mathrm{h}^{+}$trapped by the sulfur atom on the particle surface ${ }^{72}$ in $\mathrm{ZnS}$ NC. Thus, the relation of $g_{\mathrm{xx}}=g_{\mathrm{yy}}<g_{\mathrm{zz}}$ at RT is explained by the dynamical JahnTeller effect, ${ }^{77,78}$ which is probably caused by the flexible lattice motions in the NCs.
When simulating the hole EPR spectrum (green line in Figure $4 \mathrm{a}$ ) of the $\mathrm{Cu}$-doped sample at RT, the nanoseconds (ns) rotational kinetics was not required to fit the experimental data. This is in line with the anticipated large reorganization for the hole de-trapping in $\mathrm{Cu}$-doped $\mathrm{ZnS}$ NCs, as mentioned above. On the other hand, the motional effects were essential to explain the EPR line-shapes of $\mathrm{e}^{-}$ (Figure $4 \mathrm{a}$ and $4 \mathrm{~b}$ ) and $\mathrm{h}^{+}$in Figure $4 \mathrm{~b}$. These rotation kinetics strongly indicate that the $\mathrm{e}^{-}$may migrate within NCs by charge de-trappings in the powder at the ns range even after it was trapped at particle surfaces following the lightinduced charge separation in the single NC. Notably, the lifetimes of the photoinduced trap carriers were reported to be on the order of microseconds for bulk $\mathrm{ZnS}$ powder samples, ${ }^{79}$ as opposed to the minute kinetics in the NC powders (Figure 3). Sub-millisecond lifetimes were also observed by the transient absorption spectroscopy in aqueous solutions of dispersed NCs using RIPT methods (Figure S16). ${ }^{70}$ This indicated that the inhomogeneous geminate $\mathrm{e}^{-} \mathrm{h}^{+}$recombination determines trap-carrier deactivation. The highly long-lived carriers of the NC powders in Figure 3 are thus explained by ultimate interparticle charge dissociations during the ns-hoppings at particle surface area. This strongly suggests existences of several surface defect sites in the NCs, while the number of the $\mathrm{Cu}^{+}$ sites is highly limited per a $1 \% \mathrm{Cu}$-doped particle. The interparticle $\mathrm{e}^{-}$dissociations would suppress the intraparticle recombination process, playing an essential role for the present photochromic reactions.

To evaluate this, we measured photo-EPR time traces at the negative intensity positions of the first derivative signals at $B_{0}=352.2 \mathrm{mT}$ at RT, as shown in Figure S23. In both samples (ZnS NCs and Cu-doped ZnS NCs), upon UV light irradiation ( $365 \mathrm{~nm}, 100 \mathrm{~mW} \mathrm{~cm}^{-2}$ ), the EPR signals assigned to the trapped carriers gradually increased. After turning the light off, the EPR signals were still observed on a time scale of minutes. The recovery was tentatively analyzed using two-exponential decay function and the lifetimes were $36 \mathrm{~s}(55.2 \%)$ and $10 \mathrm{~min}(46.8 \%)$ for $\mathrm{Cu}$-doped ZnS NCs, while those were $26 \mathrm{~s}(41.5 \%), 5.6 \mathrm{~min}(37.2 \%)$, and a constant value (21.3\%) for undoped $\mathrm{ZnS}$ NCs. This decay time of the EPR signals was similar to that of the decoloration time of Cu-doped ZnS NCs in Figure 3b, although the decays of the EPR signals are slower than those of the decoloration process most probably due to the removal of the adsorbed water from the surface of ZnS NCs by the vacuum procedure, as shown in Figure S15. The present results in Figure S23 clearly show that the mobile charges were alive for minutes.

Furthermore, no magnetic field effect was obtained on the decoloration process at an external magnetic field strength exceeding $500 \mathrm{mT}$ (Figure S25), although the decays of the radicals are dominated by the recombination of the long-lived and separated $\mathrm{e}^{-}$and $\mathrm{h}^{+}$, as shown in Figure S24. This is explained by faster spin-relaxations in heterogeneously encountered $\mathrm{e}^{-}-\mathrm{h}^{+}$pairs than these recombinations due to the diffusive hopping motions of the carriers. Therefore, we conclude that the long-lived color is caused by the trap carriers escaped from the recombination due to the ns-hopping motions in the NC powders. 
(a)

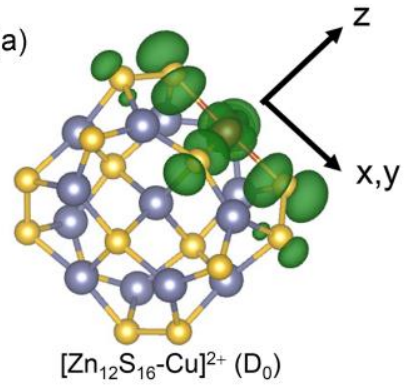

(c)

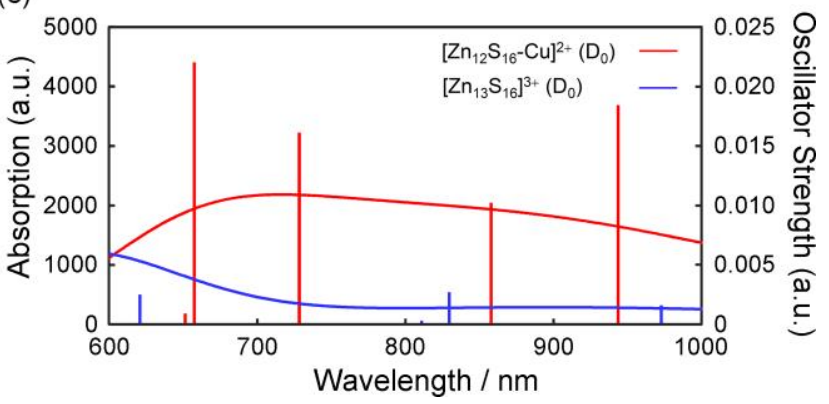

Figure 5. (a) Defect hole orbital of $\left[\mathrm{Zn}_{12} \mathrm{~S}_{16}-\mathrm{Cu}\right]^{2+}\left(\mathrm{D}_{0}\right)$ with the principal axes of the g- and HF-tensors discussed in Figure 4a. (b) Defect hole orbital of $\left[\mathrm{Zn}_{13} \mathrm{~S}_{16}\right]^{3+}\left(\mathrm{D}_{0}\right)$. (c) Computed absorption spectra (red and blue lines) as well as the oscillator strength (red and blue bars) originated from the electron excitation from the VB orbitals to the defect hole orbitals in $\left[\mathrm{Zn}_{12} \mathrm{~S}_{16}-\mathrm{Cu}\right]^{2+}\left(\mathrm{D}_{0}\right)$ and $\left[\mathrm{Zn}_{13} \mathrm{~S}_{16}\right]^{3+}\left(\mathrm{D}_{0}\right)$, respectively.

The fact that undoped ZnS NCs also exhibit long-lived carriers (Figure S23) suggests that the color is derived from the strong optical transition involving the delocalized hole created by $\mathrm{Cu}$ ion, as described above. In particular, the very weak optical absorbance (green line in Figure 3b) of the undoped $\mathrm{ZnS}$ NCs may originate from a localized hole character that causes the forbidden $\sigma-\pi^{*}$ type transition from a low-lying paired $\sigma$-orbital represented by the $\mathrm{p}_{\mathrm{z}}$ character (where the $\mathrm{z}$ axis is parallel to the $\mathrm{Zn}-\mathrm{S} \bullet$ bond) at a single sulfur site next to the zinc vacancy in the surface region. This character is similar to the molecular orbitals in the cysteine thiyl radical. ${ }^{78}$ This result agrees with the spin-orbit coupling scheme resulting in $g_{\mathrm{zz}} \approx 2.05$, which is considerably larger than $g_{\mathrm{e}}=2.002$ (free electron), while $g_{\mathrm{xx}}=g_{\mathrm{yy}}=2.001$ close to $g_{\mathrm{e}}$ is explained by the unpaired electron in the $\pi^{*}\left(\mathrm{p}_{\mathrm{x}}\right.$ or $\left.\mathrm{p}_{\mathrm{y}}\right)$ orbital which is orthogonal to the $\sigma$-orbital.

To further reveal the details of the delocalized hole and its optical transition, we calculated the stable structure, orbitals, and absorption spectra of $\mathrm{Zn}_{12} \mathrm{~S}_{16}-\mathrm{Cu}$ and $\mathrm{Zn}_{13} \mathrm{~S}_{16}$ as models of $\mathrm{Cu}$-doped and undoped $\mathrm{ZnS}$ NCs using the ab initio density functional theory (DFT), respectively (See Computational Method in the supporting information). Since an electron is well separated in NCs, we mainly focus on the ground-state doublet, $\left[\mathrm{Zn}_{12} \mathrm{~S}_{16}-\mathrm{Cu}\right]^{2+}\left(\mathrm{D}_{0}\right)$ and $\left[\mathrm{Zn}_{13} \mathrm{~S}_{16}\right]^{3+}\left(\mathrm{D}_{0}\right)$. As shown in Figure $5 \mathrm{a}$ and Figure S26, the $\mathrm{Cu}$ atom is stably connected to the surrounding $\mathrm{S}$ atoms in $\left[\mathrm{Zn}_{12} \mathrm{~S}_{16}-\mathrm{Cu}\right]^{2+}\left(\mathrm{D}_{0}\right)$. The structural changes from $\left[\mathrm{Zn}_{12} \mathrm{~S}_{16}\right.$ $\mathrm{Cu}]^{1+}\left(\mathrm{S}_{1}\right)$ and $\left[\mathrm{Zn}_{12} \mathrm{~S}_{16}-\mathrm{Cu}\right]^{1+}\left(\mathrm{S}_{0}\right)$ to $\left[\mathrm{Zn}_{12} \mathrm{~S}_{16}-\mathrm{Cu}\right]^{2+}\left(\mathrm{D}_{0}\right)$ are significant because the $\mathrm{Cu}$ defect atom did not completely fit the vacant spot originally prepared for a $\mathrm{Zn}$ atom. Interestingly, the surrounding four surface $\mathrm{Cu}-\mathrm{S}$ bonds became more symmetric in $\left[\mathrm{Zn}_{12} \mathrm{~S}_{16}-\mathrm{Cu}\right]^{2+}\left(\mathrm{D}_{0}\right)$ (Figure S26). Such significant structural rearrangement did not appear in $\left[\mathrm{Zn}_{13} \mathrm{~S}_{16}\right]^{3+}\left(\mathrm{D}_{0}\right)$.

The calculated orbital energies and shapes are shown in Figures S27-S34. The electron orbital $(125)^{\alpha}$ in $\left[\mathrm{Zn}_{12} \mathrm{~S}_{16^{-}}\right.$ $\mathrm{Cu}]^{1+}\left(\mathrm{S}_{0}\right)$ whose electron will be excited in $\left[\mathrm{Zn}_{12} \mathrm{~S}_{16}-\mathrm{Cu}\right]^{1+}$ $\left(\mathrm{S}_{1}\right)$ has a d-like orbital localized around the defect $\mathrm{Cu}$ atom as well as p-like orbitals around the $\mathrm{S}$ atoms. The excited hole orbitals $(125)^{\alpha}$ in $\left[\mathrm{Zn}_{12} \mathrm{~S}_{16}-\mathrm{Cu}\right]^{1+}\left(\mathrm{S}_{1}\right)$ and in $\left[\mathrm{Zn}_{12} \mathrm{~S}_{16}-\mathrm{Cu}\right]^{2+}\left(\mathrm{D}_{0}\right)$ still exist around the defect $\mathrm{Cu}$ atom as a d-like orbital and are also delocalized over the neighboring $\mathrm{S}$ atoms as a p-like orbital (Figure 5a and Figure S30). The rearranged $\mathrm{Cu}$ atom with the symmetrically connected surrounding $\mathrm{S}$ atoms tends to trap a hole even after the excited electron left. The delocalization of hole over $\mathrm{Cu}$ and $\mathrm{S}$ is well consistent with the above EPR results of $\rho_{\mathrm{Cu}}=0.4$ and $\rho_{\mathrm{S}}=0.6$ estimated from $A_{\mathrm{zz}}=7 \mathrm{mT}$. Importantly, the principal axes of the g- and HF-tensors (Figure 5a) are well consistent with the surface planar geometry of $\mathrm{h}^{+}$characterized by $d\left(x^{2}-y^{2}\right)$ unpaired orbital in $\mathrm{Cu}^{2+}$ hybridized with the coordinating sulfur $p_{\mathrm{x}}$ and $p_{\mathrm{y}}$ orbitals, ${ }^{73,74}$ as detailed in Figure S22. In contrast, the hole orbital $(125)^{\alpha}$ in $\left[\mathrm{Zn}_{13} \mathrm{~S}_{16}\right]^{3+}\left(\mathrm{D}_{0}\right)$ is localized around the $\mathrm{S}$ atoms as a simple p-like orbital (Figure S34).

The current DFT calculation can give a rough estimate about the trap depth $(\lambda / 4)$ as an activation energy for a hole to hop between $\left[\mathrm{Zn}_{12} \mathrm{~S}_{16}-\mathrm{Cu}\right]^{2+}\left(\mathrm{D}_{0}\right)$ and $\left[\mathrm{Zn}_{12} \mathrm{~S}_{16}-\mathrm{Cu}\right]^{1+}$ $\left(\mathrm{S}_{0}\right)$ determined by the reorganization energy of $\lambda$. The estimated trap depth, $0.34 \mathrm{eV}$, became large because of the significant surface rearrangement around the $\mathrm{Cu}$ defect atom which a ZnS NC does not possess. This large trap energy supports the absence of the hole hopping dynamics indicated by the EPR measurements.

Figure 5c shows the computed absorption spectra and the corresponding oscillator strength which could be the origin of the coloration of Cu-doped ZnS NCs. We confirmed that the interband transition, i.e. the transition from the other $\mathrm{Cu}$ orbital $(125)^{\beta}$ to the conduction band (CB), appears in the UV region, which is far above the observed visible region. The optical transitions in the shown energy range exclude any interband transitions and correspond to the experimental energy window shown in Figure 3a. Thus, all the optical transitions stemmed from the transition from the VB orbitals to the defect hole orbitals shown in Figures $5 \mathrm{a}$ and $5 \mathrm{~b}$. Remarkably, we found that, just as in Figure $3 \mathrm{a},\left[\mathrm{Zn}_{12} \mathrm{~S}_{16}-\mathrm{Cu}\right]^{2+}\left(\mathrm{D}_{0}\right)$ exhibits much stronger optical transitions compared to $\left[\mathrm{Zn}_{13} \mathrm{~S}_{16}\right]^{3+}\left(\mathrm{D}_{0}\right)$. Even the absorption to the single $\mathrm{Cu}$ hole orbital can induce such broad and strong absorption spectra owing to the delocalization of the $\mathrm{Cu}$ hole orbital (Figure $5 \mathrm{a}$ ) in addition to the existence of several VB donor orbitals. The delocalization of the $\mathrm{Cu}$ hole orbital increases the overlap of the wavefunctions between the $\mathrm{Cu}$ defect and the host $\mathrm{NC}$, resulting in the increase in the oscillator strength of the optical transition from the VB of ZnS NCs to $\mathrm{Cu}$. By contrast, the localized hole orbital of $\left[\mathrm{Zn}_{13} \mathrm{~S}_{16}\right]^{3+}\left(\mathrm{D}_{0}\right)$ shown in Figure $5 \mathrm{~b}$ resulted in the much weaker absorption. Another reason for the strong optical transition from the deep VB orbital to the $\mathrm{Cu}$ hole orbital is because the transition can be simply 


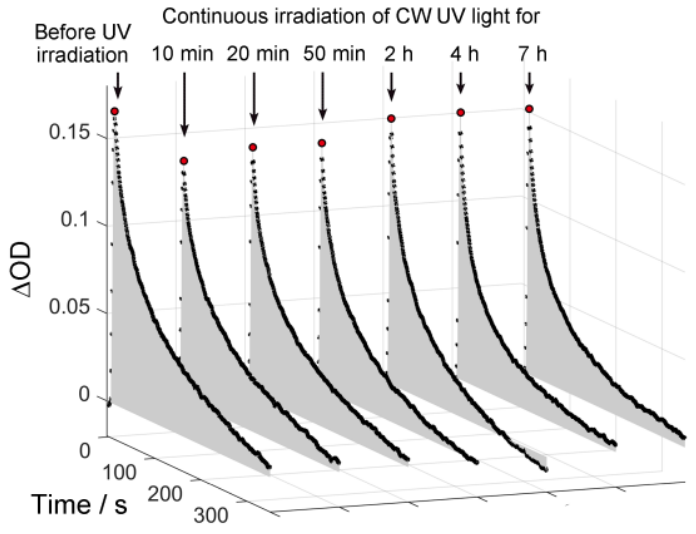

Figure 6. Time profiles of the transient diffuse reflectance of the powder of $1 \% \mathrm{Cu}$-doped $\mathrm{ZnS}$ NCs under 7 hours of UV irradiation ( $365 \mathrm{~nm}, 6.5 \mathrm{~mW} \mathrm{~cm}^{-2}$ ).

interpreted as a ligand to metal charge transfer (LMCT) transition, which has usually a large oscillator strength. The successful reproduction of the qualitative difference between the absorption spectra of $\left[\mathrm{Zn}_{12} \mathrm{~S}_{16}-\mathrm{Cu}\right]^{2+}\left(\mathrm{D}_{0}\right)$ and $\left[\mathrm{Zn}_{13} \mathrm{~S}_{16}\right]^{3+}\left(\mathrm{D}_{0}\right)$ strongly supports the picture that almost independent atomic $\mathrm{Cu}$ defects actually exist on a NC surface as drawn in Figures $5 a$ and $5 b$. It is noted that the quantitative difference in the absorption energy from Figure $3 \mathrm{a}$ is mainly due to the smaller size of the computed $\mathrm{Zn}_{12} \mathrm{~S}_{16}-\mathrm{Cu}$ compared to experimentally prepared $\mathrm{Cu}$ doped ZnS NCs; a smaller NC has sparser and fewer energy levels of orbitals in general.

To evaluate the durability of the NCs under the prolonged light irradiation, the intensity of UV light was set to $6.5 \mathrm{~mW} \mathrm{~cm}{ }^{-2}$, which was similar to the intensity of UV light containing sunlight, and the powder of $1 \%-\mathrm{Cu}$ doped $\mathrm{ZnS}$ NCs was irradiated for $7 \mathrm{~h}$. The change of optical density (OD) was measured several times (Figure 6). After $7 \mathrm{~h}$ of UV irradiation, the amplitude of $\triangle \mathrm{OD}$ and decoloration kinetics remained almost the same, which indicates that this photochromism is completely reversible. Moreover, $\mathrm{X}$ ray photoelectron spectroscopy suggested that byproducts such as $\mathrm{ZnO}$ were not formed after UV light irradiation ( $365 \mathrm{~nm}, 100 \mathrm{~mW} \mathrm{~cm}{ }^{-2}$ ) for $1 \mathrm{~min}$ at $173 \mathrm{~K}$ (Figure S35b). To further confirm the durability, 1\% Cu-doped ZnS NCs dispersed in were irradiated with CW UV light $(365 \mathrm{~nm}$, $500 \mathrm{~mW} \mathrm{~cm}^{-2}$ ) for $\sim 40 \mathrm{~min}$ in air. After irradiation, the NCs were precipitated with ethanol and dried. Notably, the XRD patterns and line widths did not change after prolonged irradiation with the CW UV light (Figure S36), which indicates that the composition and the size of ZnS NCs does not change considerably. These results suggest that $\mathrm{Cu}$-doped ZnS NCs exhibit a durable photochromic reaction, although colloidal II-VI semiconductor NCs often induce irreversible reaction pathways such as decomposition of NCs. The suppression of $\mathrm{ZnS} \mathrm{NC}$ decompositions probably due to surface ligands (MPA) because $\mathrm{ZnS}$ colloids without surface ligands readily decomposed in air with a yield of $0.32 .{ }^{80}$

The temperature dependence at outside temperature ranges is important for industrial applications of photochromic materials in various situations. Figure 7 shows the time evolution of differential diffuse reflectance before and after CW UV light irradiation ( $365 \mathrm{~nm}, 18 \mathrm{~mW} \mathrm{~cm}^{-2}$ for $5 \mathrm{~s}$ )

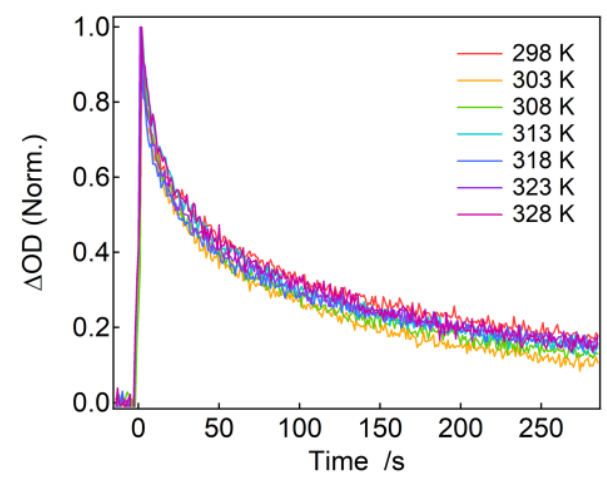

Figure 7. Time evolution of $\triangle \mathrm{OD}$ before and after CW UV light irradiation ( $365 \mathrm{~nm}, 18 \mathrm{~mW} \mathrm{~cm}^{-2}$ for $5 \mathrm{~s}$ ) of the powder of $1 \% \mathrm{Cu}$-doped $\mathrm{ZnS}$ NCs probed at $\sim 500 \mathrm{~nm}$ (the average of 490-510 $\mathrm{nm}$ ) at different temperature (298-328 K).

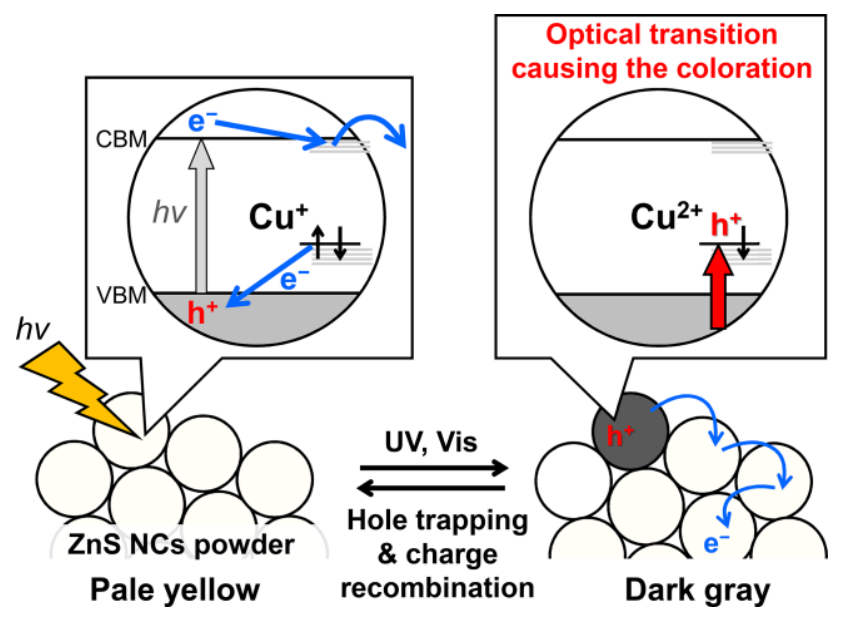

Figure 8. Plausible photochromic reaction scheme of the powder of Cu-doped ZnS NCs.

of $1 \% \mathrm{Cu}$-doped $\mathrm{ZnS} \mathrm{NC}$ powder probed at $500 \mathrm{~nm}$ at different temperatures (298-328 K). The time traces are almost the same irrespective of the different temperature. This clearly shows that the photochromic reaction of $\mathrm{Cu}$ doped $\mathrm{ZnS} \mathrm{NCs}$ is temperature-independent at these temperature ranges. This temperature independence is consistent with the efficient hopping dissociation scheme to suppress the geminate electron-hole recombination, suggesting that highly limited carrier re-encounter determines the overall recombination kinetcs. ${ }^{81}$ On the other hand, while the temperature independence at $298-328 \mathrm{~K}$ is reproducible, the rate of the decoloration below $293 \mathrm{~K}$ alters depending on the sample conditions and batches even at the same temperature. This may be due to humidity and the very small amount of the condensation at the surface of NCs. By considering to the effect of adsorbed water, another possibility for the origin of the temperature independent photochromic behavior of $\mathrm{Cu}$-doped $\mathrm{ZnS}$ NCs may be the difference in the amount of adsorbed water at the surface NC in different temperature. The decoloration processes of the T-type photochromic reactions are usually accelerated by elevating the temperature. On the other hand, the elevating temperature promotes the desorption of the adsorbed water from the surface of NCs, which will 
decelerate the decoloration process as shown Figure S15b. These complemental temperature dependences might be resulted in the temperature independent photochromic behavior of $\mathrm{Cu}$-doped $\mathrm{ZnS}$ NCs.

\section{CONCLUSION}

Figure 8 illustrates the proposed mechanism of the photochromic reaction of $\mathrm{Cu}$-doped $\mathrm{ZnS}$ NCs. Upon UV light irradiation, an excited electron and hole are generated at the conduction band minimum (CBM) and valence band maximum (VBM), respectively. These carriers are quickly trapped by surface defects and $\mathrm{Cu}^{+}$, and $\mathrm{Cu}^{+}$is oxidized to $\mathrm{Cu}^{2+}$. The electronic transition from $\mathrm{VB}$ to $\mathrm{Cu}^{2+}$ is concluded to be the origin of the coloration of the $\mathrm{Cu}$-doped $\mathrm{ZnS} \mathrm{NCs}$ from pale yellow to dark gray by the analyses using the EPR and the DFT methods. The trapped electrons are easily detrapped, resulting in the interparticle carrier migrations through the nanosecond hoppings together with the hole in ZnS NCs, while the holes could not migrate due to the large trap depth in $\mathrm{Cu}$-doped $\mathrm{ZnS}$ NCs. The electron hopping is likely the major origin of ultra long lifetimes of the trapped carriers. The long-lived trapped electron and hole gradually decay mainly by hole trapping by adsorbed water at the NC surface and charge recombination. The robust photochromic reaction of the $\mathrm{Cu}$-doped $\mathrm{ZnS} \mathrm{NCs}$, especially in the solid state, suggests the existence of a reversible chemical reaction pathway. The fast photochromic reaction of $\mathrm{Cu}$-doped $\mathrm{ZnS}$ NCs can be expanded on the basis of various molecular designs. For example, it is expected that the host NC (ZnS) can be replaced with other chalcogenide compounds such as CdS and CdSe, which would afford the visible light photosensitivity. Moreover, the use of electron-withdrawing capping reagents instead of hydrophilic capping reagents allows us to tune the rate of decoloration more precisely. Because these photochromic nanomaterials can be easily prepared with low costs, these materials posses various potentials for industrial photochromic applications. Moreover, this study demonstrated that the photochromic reaction of nanomaterials can be tuned by the lifetime of the excited carriers. Exploring novel photochromic nanomaterials utilizing ultra long-lived excited carriers are important not only for photochromic materials but also for various advanced photofunctional materials.

\section{EXPERIMENTAL SECTION}

Materials. Zinc acetate dihydrate $\left(\mathrm{Zn}\left(\mathrm{CH}_{3} \mathrm{COO}\right)_{2} \cdot 2 \mathrm{H}_{2} \mathrm{O}\right.$, 98\%, Wako), bis(2,4-pentanedionato)copper(II) $\left(\mathrm{Cu}\left(\mathrm{C}_{5} \mathrm{H}_{7} \mathrm{O}_{2}\right)_{2}\right.$, >97\%, TCI), sodium sulfide nonahydrate $\left(\mathrm{Na}_{2} \mathrm{~S} \cdot 9 \mathrm{H}_{2} \mathrm{O},>98 \%\right.$,Wako), 3-mercaptopropionicacid (MPA, $>98 \%$, TCI), sodium hydroxide (97\%, Wako), poly(ethylene glycol) bis(carboxymethyl) ether (number average molecular weight $\left(\mathrm{M}_{\mathrm{n}}\right)=250$, Sigma-Aldrich) were used without further purification.

Syntheses of ZnS NCs and Cu-doped ZnS NCs ${ }^{82}: \mathrm{Cu}-$ doped $\mathrm{ZnS}$ NCs were synthesized in aqueous solutions by using $\mathrm{Zn}\left(\mathrm{CH}_{3} \mathrm{COO}\right)_{2} \cdot 2 \mathrm{H}_{2} \mathrm{O}, \quad \mathrm{Cu}\left(\mathrm{C}_{5} \mathrm{H}_{7} \mathrm{O}_{2}\right)_{2}, \quad$ MPA and $\mathrm{Na}_{2} \mathrm{~S} \cdot 9 \mathrm{H}_{2} \mathrm{O}$. $2.5 \mathrm{mmol}$ of $\mathrm{Zn}\left(\mathrm{CH}_{3} \mathrm{COO}\right)_{2} \cdot 2 \mathrm{H}_{2} \mathrm{O}$ and $\mathrm{Cu}\left(\mathrm{C}_{5} \mathrm{H}_{7} \mathrm{O}_{2}\right)_{2}$ were dissolved in $100 \mathrm{ml}$ of deionized water. By adjusting the amount of $\mathrm{Cu}\left(\mathrm{C}_{5} \mathrm{H}_{7} \mathrm{O}_{2}\right)_{2}$, undoped $\mathrm{ZnS}$ NCs and $\mathrm{ZnS}$ NCs doped with 1\%, 3\% and 5\% (molar ratio of $\mathrm{Cu}$ to $\mathrm{Zn}$ ) of $\mathrm{Cu}$ were synthesized. Then $1 \mathrm{~mL}$ of MPA was added to the solution, and the $\mathrm{pH}$ of the mixed solution was adjusted to 10.3 with $2 \mathrm{M} \mathrm{NaOH}$. After $\mathrm{N}_{2}$ bubbling for 30 min, $2.5 \mathrm{ml}$ of $0.46 \mathrm{M} \mathrm{Na}_{2} \mathrm{~S}$ aqueous solution was quickly injected into the solution under vigorous stirring at RT. The mixture was kept for 15 min under magnetic stirring, then heated to $100{ }^{\circ} \mathrm{C}$ and lasted for $24 \mathrm{~h}$ to form the NCs. The obtained $\mathrm{Cu}$-doped ZnS NCs were precipitated by ethanol (solution: ethanol $=4: 1$ ), centrifuged $(12000 \mathrm{rpm}$ for 5 $\min )$, and then the precipitate was dried in vacuum at $45^{\circ} \mathrm{C}$.

Mixture of undoped $\mathrm{ZnS} \mathrm{NCs}$ and the $\mathrm{Cu}$ ion : $1 \mathrm{~mL}$ of $0.76 \mathrm{mM} \mathrm{Cu}\left(\mathrm{C}_{5} \mathrm{H}_{7} \mathrm{O}_{2}\right)_{2}$ aqueous solution was injected into $10 \mathrm{mg}$ of undoped ZnS NCs aqueous solution at RT and the solution was stirred until the color of the solution turned brown. Then $2 \mathrm{~mL}$ of ethanol was added to the solution and centrifuged (10000 rpm for $3 \mathrm{~min}$ ), and the precipitate was dried in vacuum at $40^{\circ} \mathrm{C}$.

Setups for Material Characterization and SteadyState Optical Measurements. The XRD was recorded in a X-ray diffractometer (Rigaku Ultima IV). The size of NCs were analysed by a TEM (JEOL JEM-2100plus) operating at $200 \mathrm{kV}$. For FTIR spectroscopies, HORIBA FT-720 FT-IR spectrophotometer combined with a ATR setup was used for solid samples (resolution: $2 \mathrm{~cm}^{-1}$ ). The absorption spectra were recorded by using a Shimadzu UV3600 UVVis spectrophotometer for solution samples, while HITACHI U-4100 with integrating sphere was used for solid samples. The photoluminescence spectra were recorded on a JASCO FP-8500 spectrofluorometer.

Time Evolution of the Diffuse Reflectance Measurements. A CW UV light with an irradiation peak at $365 \mathrm{~nm}$ from HAMAMATSU UV-LED spot light source LC-L1V3 was used as the excitation source for time evolution of the absorption measurements. OCEAN FX Spectrometers (Ocean Optics) was used as detector. The accumulation time was set to $50 \mathrm{~ms}$, and the time zero was set to the time just after stopping UV light irradiation. For temperature dependent measurements, the temperature of the powder was controlled by water chiller (NCB-2500, EYELA) and the sample temperature was measured by a type $\mathrm{K}$ thermocouple. Obtained data were analyzed by Matlab.

Sub-millisecond Transient Absorption Measurements. Sub-millisecond transient absorption spectra were measured by UNISOKU picoTAS-ps with the RIPT method. The picosecond mode-locked laser with $355 \mathrm{~nm}$ wavelength and $<25$ ps pulse width was used as pump light source. The sample was set in a quartz cell with $2.0 \mathrm{~mm}$ optical length.

EPR Measurements. Samples were degassed by the freeze-pump thaw cycling in EPR quartz tubes. The X-band cwEPR measurements were carried out using a Bruker EMX system at $\mathrm{T}=77 \mathrm{~K}$ and $\mathrm{RT}$. Light excitations were performed by a continuous $365 \mathrm{~nm}$ light of LED (THORLABS, M365LP1) with a collimate lens. Microwave conditions were as following: microwave power: $0.3 \mathrm{~mW}$; modulation amplitude: $0.4 \mathrm{mT}$. In addition, the $\mathrm{g}$ values were calibrated using a strong Pitch sample with $\mathrm{g}=$ 2.0028 as a standard. 
DFT computations. All the DFT calculations were executed by the PBE0 hybrid functional and PAW pseudopotentials with the VASP package. $\mathrm{Zn}_{12} \mathrm{~S}_{16}-\mathrm{Cu}$ was designed by replacing one of $\mathrm{Zn}$ atoms on the (110)-plane of $\mathrm{Zn}_{13} \mathrm{~S}_{16}$ by a $\mathrm{Cu}$ atom. The spin-polarization was applied and all the structures were optimized freely without any geometry constraint. The UV-VIS spectra were calculated including 60 excited states by the time-dependent density functional theory (TDDFT) implemented in the Gaussian 09 package with the PBE0 hybrid functional and def2-TZVP basis set.

\section{Supporting Information}

Details of characterizations, spectroscopic analyses, and DFT calculations. This material is available free of charge via the Internet at http://pubs.acs.org.

\section{AUTHOR INFORMATION}

\section{Corresponding Author}

*ykobayas@fc.ritsumei.ac.jp (Y. K.)

*ykobori@kitty.kobe-u.ac.jp (Y. K.)

*kim@kuchem.kyoto-u.ac.jp (K.H.-D.)

\section{ACKNOWLEDGMENTS}

This work was supported partly by JSPS KAKENHI Grant Numbers JP18K14194, JP18H05263, and Nippon Sheet Glass Foundation for Materials Science and Engineering to Y. Kobayashi, by JSPS KAKENHI Grant Numbers 19H00888, 20K21174 and Grant-in-Aid for Transformative Research Areas, "Dynamic Exciton" (JP20H05832) to Y. Kobori, and JSPS KAKENHI Grant Numbers 20K05419 and 18H05407, Toyota Mobility Foundation, and Masuya Research Foundation to K. Hyeon-Deuk. XPS measurements were conducted in JAIST, supported by Nanotechnology Platform Program (Molecule and Material Synthesis) of the Ministry of Education, Culture, Sports, Science and Technology (MEXT), Japan. The authors acknowledge Dr. Tatsuo Nakagawa, Dr. Sohshi YABUMOTO, and Mr. Hiroaki Hanada, UNISOKU Co., Ltd., for nanosecond time-resolved transient absorption measurements with the RIPT method, Dr. Daiki Fujioka and Prof. Kazuo Kojima for TEM measurements, and Dr. Tatsuya Murakami and Mr. Ichiro Kimura for XPS measurements.

\section{REFERENCES}

(1) Organic Photochromic and Thermochromic Compounds Volume 1 Main Photochromic Families; Crano, J. C., Guglielmetti, R. J., Eds.; Plenum: New York, 1999.

(2) Dürr, H.; Bouas-Laurent, H. Photochromism: Molecules and Systems; 2003.

(3) Irie, M.; Fukaminato, T.; Matsuda, K.; Kobatake, S. Photochromism of Diarylethene Molecules and Crystals: Memories, Switches, and Actuators. Chem. Rev. 2014, 114 (24), 12174-12277.

(4) Photon-Working Switches; Yokoyama, Y., Nakatani, K., Eds.; Springer Japan: Tokyo, 2017.

(5) Iwahori, F.; Hatano, S.; Abe, J. Rational Design of a New Class of Diffusion-Inhibited HABI with Fast Back-Reaction. J. Phys. Org. Chem. 2007, 20, 857-863.

(6) Fujita, K.; Hatano, S.; Kato, D.; Abe, J. Photochromism of a Radical Diffusion-Inhibited Hexaarylbiimidazole Derivative with Intense Coloration and Fast Decoloration Performance. Org. Lett. 2008, 10 (14), 3105-3108.
(7) Kishimoto, Y.; Abe, J. A Fast Photochromic Molecule That Colors Only under UV Light. J. Am. Chem. Soc. 2009, 131 (12), 4227-4229.

(8) Yamashita, H.; Abe, J. Pentaarylbiimidazole, PABI: An Easily Synthesized Fast Photochromic Molecule with Superior Durability. Chem. Commun. 2014, 50, 8468-8471.

(9) Yamashita, H.; Ikezawa, T.; Kobayashi, Y.; Abe, J. Photochromic Phenoxyl-Imidazolyl Radical Complexes with Decoloration Rates from Tens of Nanoseconds to Seconds. J. Am. Chem. Soc. 2015, 137, 4952-4955.

(10) Yamaguchi, T.; Kobayashi, Y.; Abe, J. Fast Negative Photochromism of 1,1'-Binaphthyl-Bridged Phenoxyl -Imidazolyl Radical Complex. J. Am. Chem. Soc. 2016, 138, 906-913.

(11) Tomasulo, M.; Sortino, S.; Raymo, F. M. A Fast and Stable Photochromic Switch Based on the Opening and Closing of an Oxazine Ring. Org. Lett. 2005, 7 (6), 1109-1112.

(12) Tomasulo, M.; Sortino, S.; Raymo, F. M. Amplification of the Coloration Efficiency of Photochromic Oxazines. Adv. Mater. 2008, 20 (4), 832-835.

(13) Deniz, E.; Sortino, S.; Raymo, F. M. Fluorescence Switching with a Photochromic Auxochrome. J. Phys. Chem. Lett. 2010, 1 (24), 3506-3509.

(14) Sousa, C. M.; Pina, J.; de Melo, J. S.; Berthet, J.; Delbaere, S.; Coelho, P. J. Preventing the Formation of the Long-Lived Colored Transoid-Trans Photoisomer in Photochromic Benzopyrans. Org. Lett. 2011, 13 (15), 4040-4043.

(15) Coelho, P. J.; Silva, C. J. R.; Sousa, C.; Moreira, S. D. F. C. Fast and Fully Reversible Photochromic Performance of Hybrid Sol-Gel Films Doped with a Fused-Naphthopyran. J. Mater. Chem. C 2013, 1 (34), 5387.

(16) Sousa, C. M.; Berthet, J.; Delbaere, S.; Polónia, A.; Coelho, P. J. Fast Color Change with Photochromic Fused Naphthopyrans. J. Org. Chem. 2015, 80 (24), 12177-12181.

(17) Arai, K.; Kobayashi, Y.; Abe, J. Rational Molecular Designs for Drastic Acceleration of the Color-Fading Speed of Photochromic Naphthopyrans. Chem. Commun. 2015, 51 (15), 3057-3060.

(18) Inagaki, Y.; Kobayashi, Y.; Mutoh, K.; Abe, J. A Simple and Versatile Strategy for Rapid Color Fading and Intense Coloration of Photochromic Naphthopyran Families. J. Am. Chem. Soc. 2017, 139 (38), 13429-13441.

(19) Mutoh, K.; Sliwa, M.; Fron, E.; Hofkens, J.; Abe, J. Fluorescence Modulation by Fast Photochromism of a [2.2]Paracyclophane-Bridged Imidazole Dimer Possessing a Perylene Bisimide Moiety. J. Mater. Chem. C 2018, 6 (35), 95239531.

(20) Deniz, E.; Tomasulo, M.; Cusido, J.; Yildiz, I.; Petriella, M.; Bossi, M. L.; Sortino, S.; Raymo, F. M. Photoactivatable Fluorophores for Super-Resolution Imaging Based on Oxazine Auxochromes. J. Phys. Chem. C 2012, 116 (10), 6058-6068.

(21) Ishii, N.; Kato, T.; Abe, J. A Real-Time Dynamic Holographic Material Using a Fast Photochromic Molecule. Sci. Rep. 2012, 2, 819.

(22) Ishii, N.; Abe, J. Fast Photochromism in Polymer Matrix with Plasticizer and Real-Time Dynamic Holographic Properties. Appl. Phys. Lett. 2013, 102 (16), 163301.

(23) Kobayashi, Y.; Abe, J. Real-Time Dynamic Hologram of a 3D Object with Fast Photochromic Molecules. Adv. Opt. Mater. 2016, 4 (9), 1354-1357.

(24) He, T.; Ma, Y.; Cao, Y. A.; Yang, W. S.; Yao, J. N. Improved Photochromism of $\mathrm{WO}_{3}$ Thin Films by Addition of $\mathrm{Au}$ Nanoparticles. Phys. Chem. Chem. Phys. 2002, 4 (9), 1637-1639.

(25) Wei, J.; Jiao, X.; Wang, T.; Chen, D. The Fast and Reversible Intrinsic Photochromic Response of Hydrated Tungsten Oxide Nanosheets. J. Mater. Chem. C 2015, 3 (29), $7597-$ 7603.

(26) Phipson, T. L. And on the Question of the Presence of a New Metallic Element in Commercial Zinc. Chem. News 1881, 44 (1133), 73 
(27) Phipson, T. L. On a Curious Actic Phenomenon. Chem. News 1881, 43 (1126), 283.

(28) O'Brien, W. J. A Study of Lithopone. J. Phys. Chem. 1915, 19 (2), 113-144.

(29) Goshorn, J. H.; Black, C. K. A Study of Lithopone Darkening. Ind. Eng. Chem. 1929, 21 (4), 348-349.

(30) Sviszt, P. Investigation of the Photochemical Behaviour of ZnS Single Crystals. Phys. Status Solidi 1964, 4 (3), 631-638.

(31) Piper, W. W.; Williams, F. E. Electroluminescence of Single Crystals of ZnS: Cu. Phys. Rev. 1952, 87 (1), 151-152.

(32) Dimitrova, V.; Tate, J. Synthesis and Characterization of Some ZnS-Based Thin Film Phosphors for Electroluminescent Device Applications. Thin Solid Films 2000, 365, 134-138.

(33) Hoogenstraaten, W.; Klasens, H. A. Some Properties of Zinc Sulfide Activated with Copper and Cobalt. J. Electrochem. Soc. 1953, 100 (8), 366.

(34) Handbook of Phosphors, Second Edi.; Yen, W. M., Shionoya, S., Yamamoto, H., Eds.; CRC Press.

(35) Wu, S.; Pan, Z.; Chen, R.; Liu, X. Long Afterglow Phosphorescent Materials; Spinger, 2017.

(36) Harris, D. C. Optical Properties of Infrared Windows; SPIE Optical Engineering Press: USA, 1999.

(37) Huang, J.; Yang, Y.; Xue, S.; Yang, B.; Liu, S.; Shen, J. Photoluminescence and Electroluminescence of $\mathrm{ZnS}: \mathrm{Cu}$ Nanocrystals in Polymeric Networks. Appl. Phys. Lett. 1997, 70 (18), 2335-2337.

(38) Fujiwara, H.; Hosokawa, H.; Murakoshi, K.; Wada, Y.; Yanagida, S. Surface Characteristics of ZnS Nanocrystallites Relating to Their Photocatalysis for $\mathrm{CO}_{2}$ Reduction ${ }^{1}$. Langmuir 1998, 14 (18), 5154-5159.

(39) Reddy, A. J.; Kokila, M. K.; Nagabhushana, H.; Chakradhar, R. P. S.; Shivakumara, C.; Rao, J. L.; Nagabhushana, B. M. Structural, Optical and EPR Studies on $\mathrm{ZnO}: \mathrm{Cu}$ Nanopowders Prepared via Low Temperature Solution Combustion Synthesis. J. Alloys Compd. 2011, 509 (17), 5349-5355.

(40) Panda, S. K.; Hickey, S. G.; Demir, H. V.; Eychmüller, A. Bright White-Light Emitting Manganese and Copper Co-Doped ZnSe Quantum Dots. Angew. Chem. Int. Ed. 2011, 50 (19), 44324436.

(41) Ye, H.; Tang, A.; Huang, L.; Wang, Y.; Yang, C.; Hou, Y.; Peng, H.; Zhang, F.; Teng, F. Facile One-Step Synthesis and Transformation of $\mathrm{Cu}(\mathrm{I})$-Doped Zinc Sulfide Nanocrystals to $\mathrm{Cu}_{1.94} \mathrm{~S}-\mathrm{ZnS}$ Heterostructured Nanocrystals. Langmuir 2013, 29 (27), 8728-8735.

(42) Ma, L.; Zou, X.; Bui, B.; Chen, W.; Song, K. H.; Solberg, T. X-Ray Excited ZnS:Cu,Co Afterglow Nanoparticles for Photodynamic Activation. Appl. Phys. Lett. 2014, 105 (1).

(43) Yang, H.; Holloway, P. H.; Ratna, B. B. Photoluminescent and Electroluminescent Properties of Mn-Doped ZnS Nanocrystals. J. Appl. Phys. 2003, 93 (1), 586-592.

(44) Ehlert, O.; Osvet, A.; Batentschuk, M.; Winnacker, A.; Nann, T. Synthesis and Spectroscopic Investigations of $\mathrm{Cu}-\mathrm{And}$ Pb-Doped Colloidal ZnS Nanocrystals. J. Phys. Chem. B 2006, 110 (46), 23175-23178.

(45) Xing, G. Z.; Yi, J. B.; Tao, J. G.; Liu, T.; Wong, L. M.; Zhang, Z.; Li, G. P.; Wang, S. J.; Ding, J.; Sum, T. C.; Huan, C. H. A.; Wu, T. Comparative Study of Room-Temperature Ferromagnetism in $\mathrm{Cu}$ Doped ZnO Nanowires Enhanced by Structural Inhomogeneity. Adv. Mater. 2008, 20 (18), 3521-3527.

(46) Nag, A.; Chakraborty, S.; Sarma, D. D. To Dope $\mathrm{Mn}^{2+}$ in a Semiconducting Nanocrystal. J. Am. Chem. Soc. 2008, 130 (32), 10605-10611.

(47) Xie, R.; Peng, X. Synthesis of Cu-Doped InP Nanocrystals (d-Dots) with ZnSe Diffusion Barrier as Efficient and ColorTunable NIR Emitters. J. Am. Chem. Soc. 2009, 131 (30), 1064510651.

(48) Srivastava, B. B.; Jana, S.; Karan, N. S.; Paria, S.; Jana, N. R.; Sarma, D. D.; Pradhan, N. Highly Luminescent Mn-Doped ZnS
Nanocrystals: Gram-Scale Synthesis. J. Phys. Chem. Lett. 2010, 1 (9), 1454-1458.

(49) Jana, S.; Srivastava, B. B.; Acharya, S.; Santra, P. K.; Jana, N. R.; Sarma, D. D.; Pradhan, N. Prevention of Photooxidation in Blue-Green Emitting Cu Doped ZnSe Nanocrystals. Chem. Commun. 2010, 46 (16), 2853-2855.

(50) Mocatta, D.; Cohen, G.; Schattner, J.; Millo, O.; Rabani, E.; Banin, U. Heavily Doped Semiconductor Nanocrystal Quantum Dots. Science 2011, 332 (6025), 77-81.

(51) Tobaldi, D. M.; Rozman, N.; Leoni, M.; Seabra, M. P.; Škapin, A. S.; Pullar, R. C.; Labrincha, J. A. Cu-TiO2 Hybrid Nanoparticles Exhibiting Tunable Photochromic Behavior. J. Phys. Chem. C 2015, 119 (41), 23658-23668.

(52) Tobaldi, D. M.; Hortigüela Gallo, M. J.; Otero-Irurueta, G.; Singh, M. K.; Pullar, R. C.; Seabra, M. P.; Labrincha, J. A. Purely Visible-Light-Induced Photochromism in Ag-TiO2 Nanoheterostructures. Langmuir 2017, 33 (20), 4890-4902.

(53) Tobaldi, D. M.; Lajaunie, L.; López Haro, M.; Ferreira, R. A. S.; Leoni, M.; Seabra, M. P.; Calvino, J. J.; Carlos, L. D.; Labrincha, J. A. Synergy of Neodymium and Copper for Fast and Reversible Visible-Light Promoted Photochromism, and Photocatalysis, in $\mathrm{Cu} / \mathrm{Nd}-\mathrm{TiO}_{2}$ Nanoparticles. ACS Appl. Energy Mater. 2019, 2 (5), 3237-3252.

(54) Grzelczak, M.; Liz-Marzán, L. M.; Klajn, R. StimuliResponsive Self-Assembly of Nanoparticles. Chem. Soc. Rev. 2019, 48 (5), 1342-1361.

(55) Ohko, Y.; Tatsuma, T.; Fujii, T.; Naoi, K.; Niwa, C.; Kubota, Y.; Fujishima, A. Multicolour Photochromism of TiO2 Films Loaded with Silver Nanoparticles. Nat. Mater. 2003, 2 (1), 29-31.

(56) Tatsuma, T. Plasmonic Photoelectrochemistry: Functional Materials Based on Photoinduced Reversible Redox Reactions of Metal Nanoparticles. Bull. Chem. Soc. Jpn. 2013, 86 (1), 1-9.

(57) He, T.; Ma, Y.; Cao, Y.; Hu, X.; Liu, H.; Zhang, G.; Yang, W.; Yao, J. Photochromism of $\mathrm{WO}_{3}$ Colloids Combined with $\mathrm{TiO}_{2}$ Nanoparticles. J. Phys. Chem. B 2002, 106 (49), 12670-12676.

(58) Wang, S.; Feng, X.; Yao, J.; Jiang, L. Controlling Wettability and Photochromism in a Dual-Responsive Tungsten Oxide Film. Angew. Chem. Int. Ed. 2006, 45 (8), 1264-1267.

(59) Haase, M.; Weller, H.; Henglein, A. Photochemistry and Radiation Chemistry of Colloidal Semiconductors. 23. Electron Storage on ZnO Particles and Size Quantization. J. Phys. Chem. 1988, 92 (2), 482-487.

(60) Hoyer, P.; Weller, H. Size-Dependent Redox Potentials of Quantized Zinc Oxide Measured with an Optically Transparent Thin Layer Electrode. Chem. Phys. Lett. 1994, 221 (5-6), 379-384.

(61) Liu, W. K.; Whitaker, K. M.; Kittilstved, K. R.; Gamelin, D. R. Stable Photogenerated Carriers in Magnetic Semiconductor Nanocrystals. J. Am. Chem. Soc. 2006, 128 (12), 3910-3911.

(62) Schrauben, J. N.; Hayoun, R.; Valdez, C. N.; Braten, M.; Fridley, L.; Mayer, J. M. Titanium and Zinc Oxide Nanoparticles Are Proton-Coupled Electron Transfer Agents. Science 2012, 336, 1298-1301.

(63) Joost, U.; Utka, A. S.`; Oja, M.; Smits, K.; Dö, N.; Loot, A.; Jä Rvekü Lg, M.; Hirsimä, M.; Valden, M.; Nõ, E. Reversible Photodoping of TiO2 Nanoparticles for Photochromic Applications. Chem. Mater. 2018, 30 (24), 8968-8974.

(64) Wang, X.; Li, X.; Aya, S.; Araoka, F.; Ishida, Y.; Kikkawa, A.; Kriener, M.; Taguchi, Y.; Ebina, Y.; Sasaki, T.; Koshiya, S.; Kimoto, K.; Aida, T. Reversible Switching of the Magnetic Orientation of Titanate Nanosheets by Photochemical Reduction and Autoxidation. J. Am. Chem. Soc. 2018, 140 (48), 16396-16401.

(65) Kabe, R.; Adachi, C. Organic Long Persistent Luminescence. Nature 2017.

(66) Lian, Z.; Sakamoto, M.; Kobayashi, Y.; Tamai, N.; Ma, J.; Sakurai, T.; Seki, S.; Nakagawa, T.; Lai, M. W.; Haruta, M.; et al. Anomalous Photoinduced Hole Transport in Type i Core/Mesoporous-Shell Nanocrystals for Efficient Photocatalytic H2 Evolution. ACS Nano 2019, 13 (7), 8356-8363. 
(67) Lian, Z.; Sakamoto, M.; Vequizo, J. J. M.; Ranasinghe, C. S. K.; Yamakata, A.; Nagai, T.; Kimoto, K.; Kobayashi, Y.; Tamai, N.; Teranishi, T. Plasmonic P-n Junction for Infrared Light to Chemical Energy Conversion. J. Am. Chem. Soc. 2019.

(68) Zhang, Z.; Karimata, I.; Nagashima, H.; Muto, S.; Ohara, K.; Sugimoto, K.; Tachikawa, T. Interfacial Oxygen Vacancies Yielding Long-Lived Holes in Hematite Mesocrystal-Based Photoanodes. Nat. Commun. 2019, 10 (1), 1-12.

(69) Nelson, H. D.; Gamelin, D. R. Valence-Band Electronic Structures of $\mathrm{Cu}+-$ Doped $\mathrm{ZnS}$, Alloyed $\mathrm{Cu}-\mathrm{In}-\mathrm{Zn}-\mathrm{S}$, and Ternary CuInS2 Nanocrystals: A Unified Description of Photoluminescence across Compositions. J. Phys. Chem. C 2018, 122 (31), 1812418133.

(70) Nakagawa, T.; Okamoto, K.; Hanada, H.; Katoh, R. Probing with Randomly Interleaved Pulse Train Bridges the Gap between Ultrafast Pump-Probe and Nanosecond Flash Photolysis. Opt. Lett. 2016, 41 (7), 1498.

(71) Kitagawa, H.; Kobori, Y.; Yamanaka, M.; Yoza, K.; Kobayashi, K. Encapsulated-Guest Rotation in a Self-Assembled Heterocapsule Directed toward a Supramolecular Gyroscope. Proc. Natl. Acad. Sci. U. S. A. 2009, 106 (26), 10444-10448.

(72) Nakaoka, Y.; Nosaka, Y. Electron Spin Resonance Study of Radicals Produced by Photoirradiation on Quantized and Bulk ZnS Particles. Langmuir 1997, 13 (4), 708-711.

(73) Calvo, R.; Passeggi, M. C.; Isaacson, R. A.; Okamura, M. Y.; Feher, G. Electron Paramagnetic Resonance Investigation of Photosynthetic Reaction Centers from Rhodobacter Sphaeroides $\mathrm{R}-26$ in Which $\mathrm{Fe}^{2+}$ Was Replaced by $\mathrm{Cu}^{2+}$. Determination of Hyperfine Interactions and Exchange and Dipole-Dipole Interactions between $\mathrm{Cu}^{2+}$ and QA-. Biophys. J. 1990, 58 (1), 149165.

(74) Godiksen, A.; Stappen, F. N.; Vennestrøm, P. N. R.; Giordanino, F.; Rasmussen, S. B.; Lundegaard, L. F.; Mossin, S. Coordination Environment of Copper Sites in $\mathrm{Cu}-\mathrm{CHA}$ Zeolite Investigated by Electron Paramagnetic Resonance. J. Phys. Chem. C 2014, 118 (40), 23126-23138.
(75) Suzuki, A.; Shionoya, S. Mechanism of the Green-Copper Luminescence in ZnS Crystals. I. Direct Evidence for the Pair Emission Mechanism. J. Phys. Soc. Jpn. 1971, 31 (5), 1455-1461.

(76) Gould, I. R.; Ege, D.; Moser, J. E.; Farid, S. Efficiencies of Photoinduced Electron-Transfer Reactions: Role of the Marcus Inverted Region in Return Electron Transfer within Geminate Radical-Ion Pairs. J. Am. Chem. Soc. 1990, 112 (11), 4290-4301.

(77) Yamauchi, S.; Takahashi, A.; Iwasaki, Y.; Unno, M.; Ohba, Y.; Higuchi, J.; Blank, A.; Levanon, H. The Lowest Photoexcited Triplet State of Subphthalocyanine in Solid and Fluid Environments. Time-Resolved Electron Paramagnetic Resonance Studies. J. Phys. Chem. A 2003, 107 (10), 1478-1485.

(78) Van Gastel, M.; Lubitz, W.; Lassmann, G.; Neese, F. Electronic Structure of the Cysteine Thiyl Radical: A DFT and Correlated Ab Initio Study. J. Am. Chem. Soc. 2004, 126 (7), 22372246.

(79) Wilkinson, F.; Willsher, C. J. Photoinduced Transient Absorption Within Zinc Sulphide Phosphores in Powder Form Detected by Diffuse Reflectance Laser Flash Photolysis. J. Lumin. 1985, 33, 187-199.

(80) Henglein, A.; Gutierrez, M. Photochemistry of Colloidal Metal Sulfides. 5. Fluorescence and Chemical Reactions of $\mathrm{ZnS}$ and ZnS/CdS Colloids. Ber. Bunsenges. Phys. Chem. 1983, 87 (10), 852858.

(81) Miura, T.; Tao, R.; Shibata, S.; Umeyama, T.; Tachikawa, T.; Imahori, H.; Kobori, Y. Geometries, Electronic Couplings, and Hole Dissociation Dynamics of Photoinduced Electron-Hole Pairs in Polyhexylthiophene-Fullerene Dyads Rigidly Linked by Oligophenylenes. J. Am. Chem. Soc. 2016, 138 (18), 5879-5885.

(82) Ma, L.; Chen, W. Enhancement of Afterglow in ZnS:Cu,Co Water-Soluble Nanoparticles by Aging. J. Phys. Chem. C 2011, 115 (18), 8940-8944. 
Insert Table of Contents artwork here

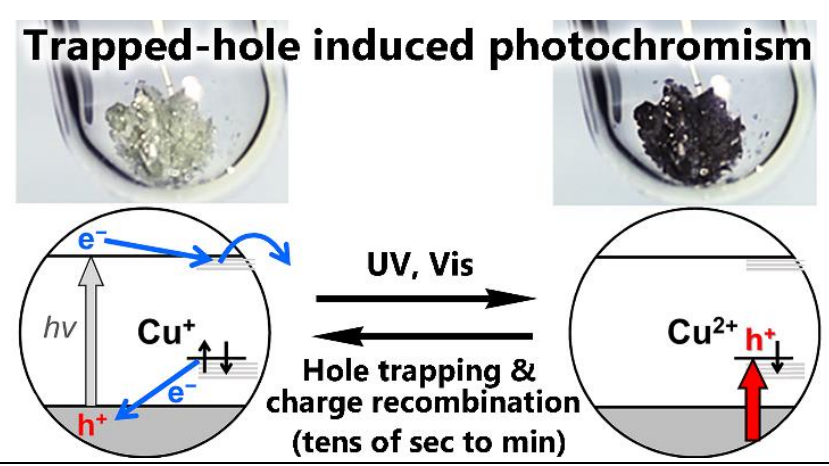

